Artigos 


\section{É a autoconsciência uma \\ forma de intencionalidade?}

Is the self-consciousness a manner of intentionality?

DOI: http://dx.doi.org/10.12957/ek.2014.15183

Prof. Dr. Pedro M. S. Alves

psalves2@gmail.com

Universidade de Lisboa - Portugal

O artigo pretende discutir a relação entre os conceitos de intencionalidade e autoconsciência na tradição fenomenológica. Para tanto, apresenta e debate tais conceitos a partir da obra de Brentano, Husserl e Sartre. A tese do artigo consiste em mostrar que boa parte da tradição fenomenológica tratou o problema da relação entre intencionalidade e autoconsciência seguindo a tese de matriz brentaniana que pode ser denominada modelo conjuntivo. Contudo, o autor propõe que exista uma outra possibilidade de se pensar tal relação, a partir do que ele denomina modelo projetivo da autoconsciência. Tal modelo pode ser explorado seguindo caminhos abertos pela filosofia husserliana.

PALAVRAS ChAVE autoconsciência. intencionalidade. fenomenologia

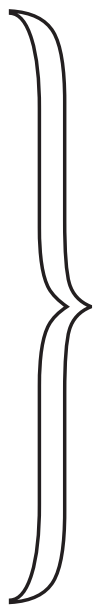

This paper aims to discuss the relation between intentionality and self-consciousness within the phenomenological tradition. In order to do this, the work of Brentano, Husserl and Sartre will be analyzed. The thesis of this paper is that most part of the phenomenological tradition has thought the relation between intentionality and self-consciousness from what we could call the conjunctive model. However there is yet another option to think it that will be present as the projective model of the self-consciousness. The last one can be developed from some Husserl's formulations.

KEYWORDS self-consciousness. intentionality. phenomenology

* O resumo do texto, bem como sua tradução correspondente, e a lista de referências bibliográficas no final do arquivo foram elaborados pelos editores da revista a fim de adequar o artigo às normas de publicação da mesma. 
Com Brentano, a caracterização do psíquico foi feita conjuntamente pela intencionalidade e pela autoconsciência. A relação entre ambas é, porém, difícil de compreender. A teoria da intencionalidade pretende ser uma descrição geral de toda consciência de qualquer coisa. No entanto, a autoconsciência parece não se adequar à descrição da intencionalidade. Primeiro, porque a autoconsciência não pode ser uma classe particular de atos intencionais, mas deve acompanhar todo e qualquer ato. Segundo, porque, ao ter de acompanhar todos os atos intencionais, não pode ter uma estrutura idêntica à deles, sob pena de isso envolver uma regressão ao infinito. A resposta de Brentano para a dificuldade consistiu em defender (i) que toda a consciência de objeto é auto-representativa, (ii) que esta autoconsciência se verifica no mesmo nível da consciência intencional, (iii) que à direção para um objeto (intencionalidade) se conjuga sempre uma direção "oblíqua" para si mesmo (autoconsciência) em todo e qualquer ato intencional.

Chamo a isto o modelo conjuntivo: todo ato é consciência de objeto e consciência de si próprio (enquanto consciência de objeto). Apresento a teoria da consciência pré-reflexiva, de Jean-Paul Sartre, como um caso típico de modelo conjuntivo dentro da tradição fenomenológica. Discuto a posição de Husserl sobre a dupla intencionalidade da retenção, tentando mostrar que ela não pode ser interpretada como uma adesão sem reservas ao modelo conjuntivo.

Finalmente, exponho a minha tese sobre o que designo como modelo projectivo da autoconsciência. De acordo com ele, o "eu" da autoconsciência não está "atrás", por assim dizer, acessível apenas numa consciência oblíqua ou pré-objetivante; o eu da autoconsciência está "em frente", no próprio objeto da consciência intencional. Defendo que a consciência perceptiva é "auto-posicional" e que a auto-representação se pode descrever como o ponto-de-vista a partir do qual a experiência objetual se organiza. Defenderei, portanto, uma revisão de algumas das teses mais disseminadas na literatura fenomenológica.

Neste estudo, quero defender o seguinte:

1. Que a tradição fenomenológica permaneceu, em grande parte, vinculada a teses brentanianas acerca da intencionalidade e da autoconsciência;

2. Que, nomeadamente, ela permaneceu ligada a um modelo conjuntivo de relação entre ato intencional e consciência de si;

3. Que um caso significativo desta herança brentaniana é a análise de Sartre sobre a dimensão pré-reflexiva da consciência de 
si, a qual recebe o nome de cogito pré-reflexivo;

4. Que o modelo conjuntivo tem, porém, não só dificuldades conceptuais, como não assenta em qualquer evidência fenomenológica diretamente comprovável;

5. Que a Fenomenologia tem, no entanto, outras possibilidades em aberto e ainda em boa parte por explorar no que diz respeito à conexão entre intencionalidade e autoconsciência;

6. Que, em particular, a descoberta husserliana de um mundo perceptivo dado numa experiêcia antepredicativa, a que chamou Lebenswelt, permite, indo um pouco mais longe na exploração das suas estruturas, enquadrar a consciência de si na intencionalidade de um modo concreto e, a meu ver, mais respeitador das evidências que uma análise fenomenológica pode fornecer.

\section{Três teses de Brentano sobre o psíquico}

\section{Um - Autoconsciência}

Como é sabido, Brentano distinguiu entre Psicologia genética e Psicologia descritiva. A versão de Psicologia que desenvolveu sob a designação de "Psicologia de um ponto de vista empírico" (Psychologie vom empirischen Standpunkt, 1874) era a forma descritiva da ciência psicológica. $\mathrm{O}$ "ponto de vista empírico" não significava, portanto, o estudo dos fenômenos psíquicos do ponto de vista objetivo-causal, através de qualquer aparato experimental, ponto de vista que deixa portas abertas para rebater o psíquico no fisiológico e, mais além ainda, o fisiológico no biológico e o biológico no físico. Esse ponto de vista empírico significava, antes, o estudo dos fenômenos psíquicos tal qual se mostram ao ou tal qual são vividos pelo próprio sujeito de cuja "vida psíquica" eles fazem parte.

Segundo as caracterizações hoje em uso, isto significa que "empírico" era, para Franz Brentano, o estudo dos fenômenos psíquicos do ponto de vista da primeira-pessoa. No entanto, esta posição brentaniana envolve um ensinamento mais profundo. Não se trata, de fato, apenas de dizer que os "fenômenos psíquicos" podem ser abordados quer do ponto de vista da terceira-pessoa, quer do ponto de vista da primeira-pessoa, ou seja, tal como são intuídos pelo sujeito 
que os vive como "seus". Mais importante que isso, a ideia de fundo de Brentano era, em minha opinião, a de que o que os caracterizava como fenômenos, e como fenômenos psíquicos, era precisamente o fato de envolverem aquilo que chamarei, pondo-me da perspectiva fenomenológica, uma "estrutura de aparição" (Erscheinung), e de essa aparição ter o sentido de uma "auto-aparição" (Selbsterscheinung). Husserl falou de um Für sich selbst erscheinen do sujeito nas suas vivências (Erlebnisse). De fato, só quando há algo como uma auto-aparição é que poderemos falar tanto de uma vida psíquica, distinta da base fisiológica e biológica, puramente descritível do ponto de vista objetivo, como de um sujeito que tem essa vida como sua própria vida. Um mundo destituído de fenômenos psíquicos, neste sentido particular, seria um mundo destituído de sujeitos: podia certamente continuar a haver entidades que, no mundo objetivo, realizassem as operações que identificamos com o psíquico, não haveria nesse mundo, porém, sujeitos que aparecessem a si mesmos e que para si mesmos se compreendessem como sujeitos de uma vida psíquica e que pudessem reportar os seus estados internos em asserções como "eu sinto", "eu imagino", "eu desejo", etc.

Assim, o fundamental da distinção de Brentano não está em que associemos o ponto de vista da primeira pessoa à Psicologia descritiva e que associemos o ponto de vista da terceira pessoa à Psicologia genética. O fundamental é que, para Franz Brentano, um fenômeno é psíquico na medida em que tem uma estrutura de auto-aparição. E isso significa: ele é o lugar de surgimento de uma vida mental, distinguível dos estratos biológico e físico-químico, e de um sujeito dessa vida, que a tem como sua própria vida. Ou seja, o que Brentano está sugerindo é que só quando há o ponto de vista da primeira pessoa é que haverá algo como um fenômeno psíquico, distinto dos fenômenos fisiológicos e biológicos subjacentes, e que, para efetuar um estudo do psíquico do ponto de vista da terceira pessoa, é preciso que os fenômenos psíquicos tenham sido previamente delimitados recorrendo ao ponto de vista da primeira pessoa. Trata-se de uma precedência da Psicologia descritiva relativamente à Psicologia genética. Assim, a lição mais profunda de Franz Brentano será, em minha opinião, a de que é insuficiente dar uma definição de ato psíquico que elimine ou desconsidere esta dimensão de auto-aparição, ou, para utilizar as expressões hoje em uso, provenientes de Nagel, esta dimensão "experiencial" em que, para o sujeito, "é como alguma coisa" ("it is like to be") ter esta ou aquela vivência psíquica.

Brentano designava este aspecto auto-aparencial (innere Vorstellung) do psíquico como algo captado numa innere Wharnehmung, numa percepção 
interna. Percepção interna era a imediata captação dos atos psíquicos "por si próprios", ou seja, a característica de estarem conscientes. Brentano distinguia entre percepção interna e observação interna (innere Beobachtung). Enquanto a observação interna era um segundo ato voltado para o ato primário, que envolvia memória e estava sujeito a erro, a per-cepção interna era intrínseca ao próprio ato e excluía, por isso, a possibilidade de erro. Para Brentano, esta imunidade ao erro fazia dela a forma canônica de percepção (Whar-nehmung - à letra, captação do verdadeiro).

Chamamos doravante "autoconsciência" a esta putativa percepção interna.

Enunciamos assim a tese de Brentano:

T1 Todo ato psíquico é autoconsciente - ele envolve uma auto-aparição.

Como Brentano escreveu,

Todo ato psíquico é consciente, está nele próprio dada uma consciência de si próprio. [...] O fenômeno psíquico [...] está de uma tríplice maneira na consciência. Ela representa-o, conhece-o e sente-o. ${ }^{1}$

Esta tese brentaniana equivale, obviamente, há asserção de que não há atos psíqui-cos inconscientes. Na sua Psicologia, Brentano dedicou um grande esforço argumentativo para excluir esta possibilidade.

\section{Dois - Intencionalidade}

Brentano deu, a par da autoconsciência, outros critérios para distinguir entre fenômenos psíquicos e físicos. Entre eles, figurava o célebre critério da intencionalidade, que, para Brentano, era também o mais apropriado para caracte-

1 Eis a passagem completa: „Jeder psychische Act ist bewusst; ein Bewusstsein von ihm ist in ihm selbst gegeben. Jeder auch noch so einfache psyschische Act hat darum ein doppeltes Object, ein primäres und ein secundäres, Der einfachste Act, in welchem wir hören, z. B. hat als primäres Object den Ton, als secundäres Object aber sich selbst, das psychische Phänomen, in welchem der Ton gehört wird. Von diesem zweiten Gegenstande ist er in dreifacher Weise ein Bewusstsein. Er stellt ihn vor, er erkennt und fühlt ihn". Franz Brentano - Psychologie vom empirischen Standpunkt. Leipzig: Verlag von Duncker \& Humblot. 1874, Erster Band, Buch II, Capitel 3, p. 202 
rizar os atos psíquicos. Apesar de ser talvez o trecho mais citado de Brentano, na literatura fenomenológica e não só, vale a pena ler as suas palavras uma vez mais. Dizem o seguinte:

Todo fenômeno psíquico é caracterizado por aquilo que os escolásticos da Idade Média chamaram a inexistência intencional (ou também mental) de um objeto, e que nós poderíamos cha-mar, se bem que não de um modo totalmente isento de ambiguidades, referência a um conteúdo, direção para um objeto [...] ou objetividade imanente. Todos os fenômenos psíquicos incluem qualquer coisa como objeto no interior de si próprios, se bem que não o façam todos da mesma maneira. $\mathrm{Na}$ representação, algo é representado, no juízo, algo é afirmado ou negado, no amor, amado, no ódio, odiado, no desejo, desejado, etc. ${ }^{2}$

Estas formulações estão pejadas de ambiguidades. Para lá da questão de a intencio-nalidade ser ou não uma propriedade intrínseca e não-redutível do psíquico, é um tópico recorrente dos comentários a distinção entre uma caracterização ontológica da intencionalidade, centrada na discussão da natureza da "objetividade imanente", e uma caracterização psicológica, concentrada em torno da expressão "direção para um objeto". Brentano crê que os fenômenos psíquicos têm intrinsecamente a propriedade de se dirigem ou se referirem a um objeto que existe em o ato (inexiste nele), se bem que seja necessário aclarar ainda em que consiste este objeto enquanto correlato do ato e qual a sua relação com o objeto real. Twardowski, Meinong e Husserl tiveram uma larga participação no debate sobre a natureza dessa objetividade imanente. Tal como para Brentano, o fato de podermos pensar objetos impossíveis (o quadrado-redondo) ou inexistentes (Afrodite) foi uma forte motivação para manter este conceito de um "objeto intencional" inexistente no ato. Husserl, de que me ocuparei mais adiante, deu, nas Investigações Lógicas, uma solução que constitui

2 ,Jedes psychische Phänomen ist durch das charakterisiert, was die Scholastiker des Mittelalters die intentionale (auch wohl mentale) Inexistenz eines Gegenstandes genannt haben, und was wir, obwohl mit nicht ganz unzweideutigen Ausdrücken, die Beziehung auf einen Inhalt, die Richtung auf ein Objekt [...], oder die immanente Gegenständlichkeit nennen würden. Jedes enthält etwas als Objekt in sich, obwohj nicht jedes in gleicher Weise. In der Vorstellung ist etwas vorgestellt, in dem Urtheile ist etwas anerkannt oder verworfen, in der Liebe, geliebt, in dem Hasse gehasst, in dem Begehren begehrt u.s.w." Idem, p. 115. 
uma restauração do simples bom-senso, a qual está firmada no aspecto noético da intencionalidade. Para ele, a intencionalidade não pode ser descrita como uma relação real com um objeto extraor-dinário, o "objeto intencional”, mas como uma relação não-real com um objeto ordinário. No apêndice da Quinta Investigação, em que critica a teoria das imagens, o seu motto é que objeto real e objeto intencional são o mesmo, pois, de outro modo, o ato intencional não seria acerca do próprio objeto real, mas sim acerca de outra coisa diferente. $\mathrm{E}$ a justificação acentua o fato de a intencionalidade ser sobretudo definida como direcionalidade para algo, como um visar. Nas suas palavras,

O objeto intencional da representação é o mesmo que o seu objeto efetivo e, se for o caso, exterior, e é um contra-senso distinguir entre ambos. [...] Dizer que o objeto é "simplesmente intencional" não significa: ele existe, se bem que apenas na intentio [...], ou existe aí uma qualquer sombra do objeto, mas quer antes dizer: a intenção, que "visa" um objeto assim constituído, existe, mas não o objeto. Se, por outro lado, o objeto intencional existe, então não existe simplesmente a intenção, o visar, mas também o visado. ${ }^{3}$

Seja o que se diga acerca do estatuto ontológico do "objeto intencional", mesmo de-pois de Husserl ter incorporado a dimensão "fansiológica" ou "noemática" da intenciona-lidade, uma coisa permanece como um traço brentaniano na tradição fenomenológica: a tese de que a relação intencional é uma nota intrínseca do mental e que ela envolve sempre uma cisão entre dois termos extremos que têm sempre de ser distinguidos, se bem que as caracterizações de um e outro possam variar, a saber, o ato intencional com a sua qualidade própria (representação, juízo, desejo, etc.) e matéria, de um lado, e o objeto que é visado, do outro, a que se vem ainda juntar um termo intermédio: o conteúdo significativo através do qual o objeto é visado ou, como Husserl celebremente disse no parágrafo 131 das Ideias, o "conteúdo noemático" enquanto "objeto

3 ,Der intentionale Gegenstand der Vorstellung derselbe ist wie ihr wiklicher und gegebenfalls $\mathrm{ihr}$ äusserer Gegenstand und dass es wiedersinnig ist, zwischen beiden zu unterscheiden. [...] De Gegenstand ist ein „blosser intentionaler“, heisst natülich nicht: er existiert, jedoch nur in der intentio [...], oder es existiert darin irgendein Schatten von ihm; sondern es heisst: die Intention, das einen so beschaffenen Gegenstand „Meinen“ existiert, aber nicht der Gegenstand. Existiert andererseits der intentionale Gegenstand, so existiert nicht bloss die Intention, das Meinen, sondern auch das Gemeinte." Edmund Husserl - Logische Untersuchungen. Band XIX/1. The Hague: Martinus Nijhoff Publishers, 1984, pp. 439-40. 
no como das suas determinações" (Gegenstand im Wie seiner Bestimmtheiten).

Assim, a segunda tese de Brentano que quero sublinhar é a seguinte:

T2 Todo ato psíquico é consciência de algo - ele envolve um objeto

$$
\text { diferente dele }
$$

\section{Três - Consciência autoconsciente}

Os outros critérios brentanianos não me interessam aqui. O que é importante para os meus objetivos imediatos é o modo como Brentano conjuga as suas teses 1 e 2, a saber, a tese de todo ato psíquico é autoconsciente e a tese de que todo ato psíquico é consciência de uma coisa dele diferente.

Como se conjugam consciência e autoconsciência? As decisões teóricas de Brentano consistem, em substância, no seguinte: primeiro, na tese de que toda consciência de objeto é já auto-representativa, ela é uma innere Vorstellung, se bem que não ainda um juízo, Urteil, no sentido brentaniano de uma tomada de posição relativamente ao objeto de uma simples representação; segundo, que esta autoconsciência se realiza no próprio ato intencional que está dirigido para um objeto dele diferente; terceiro, que à direção para um objeto diferente do ato (a intencionalidade, em sentido próprio) se conjuga sempre uma direção "oblíqua" do ato para si mesmo, enquanto objeto secundário, em todo e qualquer ato intencional.

Assim, a terceira tese de Brentano acerca dos atos psíquicos é a seguinte:

\section{T3. Ser-consciente envolve o objeto de que se está consciente e a consciência disso.}

Deste modo, Brentano deu respostas muito precisas a várias questões controversas. Nomeadamente: (i) que há uma consciência de si anterior à reflexão, e que ela é independente de qualquer ato de segunda ordem; (ii) que não será possível desligar intencionalidade e autoconsciência, de modo que a consciência de si próprio será um elemento que não poderá ser eliminado numa teoria satisfatória acerca da consciência de objeto; (iii) que, na unidade de um mesmo ato psíquico, estão dados dois objetos: um objeto primário, ou objeto 
intencional do ato, e, concomitantemente, um objeto se-cundário, o próprio ato intencional; (iv) que esta consciência do objeto secundário já não pode ser plenamente descrita em termos análogos aos da consciência do objeto primário, ou da intencionalidade em sentido estrito, se bem que, algo paradoxalmente, se use ainda o termo tipicamente intencional de "direção para...".

Daí que as posições teóricas de Brentano tenham legado outros tantos problemas de difícil solução. Pergunto:

1. Há efetivamente uma consciência de si pré-reflexiva, embutida na consciência de objeto?

2. Pode esta consciência de si ser descrita ainda como uma consciência intencional?

3. Quem é o sujeito desta consciência de si?

4. $\quad$ E qual o teor desta autoconsciência, quer tomada em si própria, quer na sua relação com a consciência intencional?

São estas perguntas que me proponho tratar, olhando agora mais de perto para a tradição fenomenológica.

Começarei com Sartre e recuarei até Husserl.

\section{Sartre e Husserl sobre autoconsciência}

\section{Um - Sartre}

Brentano afirmara que, num mesmo ato, se conjugam a representação de, por exem-plo, um som $e$ a representação da representação do som. Chamo a esta tese o modelo conjuntivo: todo ato é consciência de objeto e consciência de si próprio enquanto consciência de objeto. Esta consciência não é um saber de que estamos ouvindo um som. Isso seria um ato de segunda ordem. Ela é a consciência de som consciente dela mesma, e esta consciência não é mais consciência-de, não é transitiva, e acerca dela falha o esquema intencional, com a polarização entre ato, conteúdo significativo e objeto. A minha conviç̧ão é que nem Brentano nem a tradição fenomenológica que vai beber à sua fonte têm uma descrição convincente desta suposta autoconsciência.

Olhemos desde já para o caso daquele que é talvez o maior teórico desta autocons-ciência na literatura fenomenológica: Jean-Paul Sartre. Efectivamente, 
mesmo que ele não o soubesse, a teoria de Sartre é um brentanismo radicalizado no que respeita à conexão entre consciência e autoconsciência. E isto porque, na descrição de Sartre, a autoconsciência já não está obliquamente voltada para um segundo objeto, mas coincide inteiramente com a consciência do objeto intencional. De fato, segundo Sartre, a intencionalidade é uma relação com o objeto que exaure a consciência. Na sua expressão, ela é "arrachement à soi", relação com um "dehors", um fora, onde nada como um "objeto secundário" fica ainda como resto. Desde La transcendence de l'ego, de 1936, que Sartre defende uma teoria não-egológica da consciência: nela não há um ego que se contra-distinga do objeto intencional e que seja para si mesmo dado numa consciência lateral, através do ato psíquico que dele supostamente emana, mas, pelo contrário, a consciência é, toda ela, uma consciência de objeto consciente dela própria. Nas suas palavras:

Com efeito, a existência da consciência é um absoluto porque a consciência é consciência dela mesma. Quer dizer que o tipo de existência da consciência é ser consciência de si. E ela toma consciência de si enquanto ela é consciência de um objeto transcendente. Tudo é, pois, claro e lúcido na consciência: o objeto está perante ela com a sua opacidade característica, mas ela, ela é pura e simplesmente consciência de ser consciência desse objeto. ${ }^{4}$

Esta autoconsciência envolve as seguintes duas notas importantes:

$1^{\circ}$ A autoconsciência é irreflectida, ou seja, ela não está em trânsito para uma consciência reflexiva ou de segunda ordem, mas é, em si mesma, uma consciência de si sem reflexão.

$2^{\circ}$ A autoconsciência é não-posicional, ou seja, ela não envolve uma expressa afirmação de si mesma, mas a sua existência é parasitária da consciência posicional do objeto transcendente e coincide com ela.

4 « En effet, l'existence de la conscience est un absolu parce que la conscience est consciente d'elle-même. C'est-à-dire que le type d'existence de la conscience c'est d'être conscience de soi. Et elle prend conscience de soi en tant qu'elle est conscience d'un objet transcendant. Tout est donc clair et lucide dans la conscience : l'objet est en face d'elle avec son opacité caractéristique, mais elle, elle est purement et simplement conscience d'être conscience de cet objet, c'est la loi de son existence.» Jean-Paul Sartre - La transcendence de l'ego. Esquisse d'une description phénoménologique. Paris : Vrin, 1966, pp. 23-24. 
Para terminar com as citações de Sartre, vejamos o modo como ele se exprime a este respeito em La transcendence de l'ego:

Esta consciência de consciência não é posicional, ou seja, a consciência não é a si própria o seu objeto. O seu objeto está fora dela por natureza e é por isso que, num mesmo ato, ela o põe e o apreende. Ela própria não se conhece senão como interioridade absoluta. Chamaremos a uma tal consciência consciência do primeiro grau ou irreflectida. ${ }^{5}$

Desta descrição seguem-se dois corolários que serão importantes na minha argu-mentação posterior. O primeiro é o da autonomia da consciência irreflectida, ou seja, a como que auto-suficiência desta forma de autoconsciência: ela não estaria em desequilíbrio para a reflexão, não precisaria de uma consciência de segunda ordem, e, como Sartre afirma em outro lugar, seria mesmo concebível uma consciência de si irrefletida que nunca desse lugar a um ato de reflexão. Sartre retomou, numa conferência em 1945, na Sociedade Francesa de Filosofia, a distinção kantiana entre consciência de si e conhecimento de si. Esta afirmação da autonomia e da auto-suficiência do cogito irrefletido é justamente a afirmação de uma consciência de si sem conhecimento de si. O segundo corolário é que Sartre efetua como que uma petrificação da distinção brentaniana, de que Husserl fora o crítico, entre "interior" e "exterior": o objeto da cons-ciência intencional está "fora" dela e a consciência é, perante ele, como Sartre diz no tex-to acima, uma "interioridade absoluta". Ficamos, portanto, com uma autoconsciência em que o seu sujeito se aparece como pura interioridade.

Mas há mesmo uma coisa tal? É de duvidar que exista algo como esta autoconsciência irreflectida e não-posicional cuja descrição encontramos em Sartre. E haverá mesmo fundadas suspeitas de que ela seja construída por uma espécie de ilusão retrospectiva a partir da consciência reflexiva.

O ponto forte da descrição de Sartre, ou de qualquer outra teoria da autoconsciência não-reflexiva, é o fato de qualquer sujeito - pelo menos humano

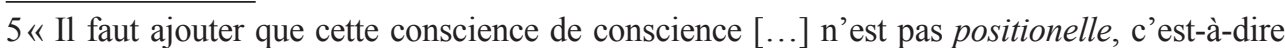
que la conscience n'est pas à elle-même son objet. Son objet est hors d'elle par nature et c'est pour cela que d'un même acte elle le pose et le saisit. Elle-même ne se connaît que comme intériorité absolue. Nous appellerons une pareille conscience : conscience du premier degré ou irréfléchie. » Idem, p. 24. 
- ter a capacidade de reportar os acontecimentos da sua vida psíquica. Nomeadamente, quando estamos absortos, por exemplo, na observação de uma cena, temos consciência dos objetos, das suas relações, dos acontecimentos que vão ocorrendo, e podemos estar tão focados na observação que como que nos "esquecemos de nós mesmos" e não temos nem uma consciência lateral do nosso ato de observar, nem, muito menos, uma consciência de segunda ordem, que tome como objeto esta consciência voltada para a cena objectiva; todavia, se nos interrompem subitamente e nos perguntam o que fazemos, sabemos imediatamente dizer, sem inferência, o que estávamos fazendo; neste caso, que estávamos observando e ouvindo tal ou tal cena. Esta possibilidade, sempre presente, de reportar atividades psíquicas não expressamente conscientes parece ser uma evidência em prol da tese sartreana, mas também brentaniana, de uma autoconsciência ante-reflexiva que pode bem ser minimal, mas que nunca estará, porém, completamente ausente. De fato, assim argumentam os teóricos da autoconsciência, se não houvesse já uma consciência pré-reflexiva do ato de ver, jamais poderíamos tomar, subsequen-temente, uma consciência expressa de que víamos, num ato de segunda ordem, pois, então, esse primeiro ato seria inconsciente e nada seria nada para nós.

Esta tese da autoconsciência não se baseia em qualquer evidência direta. $\mathrm{Na}$ verdade, uma observação da suposta autoconsciência seria um ato de reflexão que a alteraria. Sartre, em La transcendence de l'ego, afirma que a memória retencional mantém ainda presente a vivência anterior e permite uma quase-observação do teor desta autoconsciência tal como ela era antes da observação. No entanto, a memória, mesmo que fresca, é já um novo ato que incide sobre o primeiro, e, se esta autoconsciência é "interioridade absoluta", como ele o diz, como poderia ela estar exposta para um outro ato que a objetivaria? $\mathrm{O}$ fenomenólogo adepto desta tese da autoconsciência irrefletida tem, portanto, aqui, não um dado diretamente verificável, mas apenas um argumento baseado na possibilidade permanente de reportar a atividade psíquica própria. Porque podemos sempre reportar, ou seja, objetivar numa consciência reflexiva, de segunda ordem, um ato intencional, supõe-se, então, que o ato reportado estava já autoconsciente e apresenta-se esta autoconsciência como algo que se conjuga com a consciência de objeto; diz-se: todo ato psíquico é consciência de alguma coisa e ao mesmo tempo de si próprio. De seguida, precisa-se que esta consciência de si próprio já não é um ato intencional, a fim de se evitar uma óbvia regressão ao infinito, pois esse ato precisaria ainda de um outro para estar consciente e assim sucessivamente. Aos teóricos da inten-cionalidade como propriedade essencial e não-redutível do psí $\neg$ quico depara-se-lhes, assim, uma 
forma de consciência não-intencional, que já não é sequer possuidora de um objeto. O problema é saber se esta é a única e a mais convincente interpretação desta possibilidade de reportar.

Recentemente, o fenomenólogo Dan Zahavi, também um adepto desta tese, tentou reforçar os argumentos a seu favor afirmando que há uma diferenciação qualitativa e experiencial no seio da autoconsciência. A sua argumentação recorre ao tópico nageliano do "what it is like". As suas palavras são as seguintes:

A noção de autoconsciência pré-reflexiva está relacionada com a ideia de que as experiências têm um "toque" [feel] para elas, uma certa qualidade (fenomenal) "do que é como" ['what it is like'] ou a que é que "sabe" [what it 'feels' like] tê-las. Tal como é usualmente expresso fora dos textos fenomenológicos, ter uma experiência consciente significa necessariamente que, para o sujeito, há alguma coisa que é como ter essa experiência. No entanto, há mais para experienciar do que o fato de que o que é como perceber um triângulo negro é subjetivamente diferente daquilo que é como perceber um círculo vermelho. Não só o que é como perceber vermelho é diferente daquilo que é como perceber negro, mas também o que é como perceber vermelho é diferente daquilo que é como recordar vermelho ou imaginar vermelho. ${ }^{6}$

Numa palavra, esta suposta autoconsciência não só pervade todas as consciências intencionais, coisa que Sartre e Brentano já haviam dito, como terá um verdadeiro poder interno de discriminação acerca do teor tanto dos qualia (vermelho, negro), como daquilo que os fenomenólogos chamam a "qualidade" dos atos (perceber, imaginar, recordar, desejar, etc.). Dan Zahavi tem certamente razão quando estende a noção de qualidade fenomenal também às vivências e

6"The notion of pre-reflective self-consciousness is related to the idea that experiences have a subjective 'feel' to them, a certain (phenomenal) quality of 'what it is like' or what it 'feels' like to have them. As it is usually expressed outside of phenomenological texts, to undergo a conscious experience necessarily means that there is something it is like for the subject to have that experience. However, there is more to experience than the fact that what it is like to perceive a black triangle is subjectively distinct from what it is like to perceive a red circle. Not only is what it is like to perceive red different from what it is like to perceive black, but what it is like to perceive red is different from what it is like to remember or imagine red." Shaun Gallaguer e Dan Zahavi - The Phenomenological Mind. London: Routledge, 2008, p. 49. 
deixa de a confinar aos sense data. Para o sujeito, perceber uma parede branca é subjetivamente diferente de perceber uma parede verde, mas também perceber uma parede é, para o sujeito, diferente de imaginar uma parede. No entanto, se perguntarmos em que consiste essa diferença e como pode ela expressar-se, Dan Zahavi só pode responder:

- A diferença está no toque subjetivo com que perceber e imaginar são "sentidos" na autoconsciência, e isso não pode ser expresso numa linguagem conceptual e comunicado, mas apenas experienciado pelo próprio sujeito.

Eu, porém, contornando esta necessidade de afirmar a existência de uma autocons-ciên $\neg$ cia discriminadora concomitante com as vivências intencionais, preferiria responder:

- A diferença está no próprio sentido com que os objetos intencionais aparecem - aparecer como coisa imaginada é diferente de aparecer como coisa percebida, e essa diferença não é um "sentimento" subjetivo e inefável, mas equivale a uma modalidade de comportamento diferente para com os objetos percebidos ou imaginados no nosso mundo circundante: nomeadamente, enquanto paro diante de paredes percebidas, atravesso sem pestanejar paredes imaginadas.

Como é bem visível, a diferença entre estas duas respostas não está em que se negue al $\neg$ go como uma consciência de si na consciência de objeto, mas sim no lugar onde ela deve ser posta. Enquanto os teóricos da autoconsciência provindos de Brentano crêem que a intencionalidade está dirigida para um objeto diferente do ato e que a autoconsciência dá, por assim dizer, um passo atrás e se dirige para o próprio ato, criando uma espécie de diplopia mental, eu creio que há uma representação concreta de si no próprio modo como os objetos intencionais aparecem e no sentido com que eles são visados.

Terminarei desenvolvendo esta tese. Antes, porém, quero mostrar que a tradição fenomenológica não está toda ela comprometida com a versão brentaniana da autoconsciência. Um caso notável de não-adesão plena, ou de adesão crítica, ao modelo conjuntivo brentaniano é, por mais paradoxal que isso possa soar, a do próprio fundador da Fenomenologia. Refiro-me, bem entendido, a Edmund Husserl. Encontramos nele o embrião para uma interpretação diferente da possibilidade de reportar a nossa vida mental. 


\section{Dois - Husserl}

No início da Quinta Investigação, publicada em 1901, Husserl distinguira três sentidos de consciência: consciência como totalidade das vivências pertencentes ao um ego ( $a$ consciência), consciência como percepção interna das próprias vivências (a autoconsciência), e consciência enquanto vivência intencional (a consciência de). Nas Investigações Lógicas, e em particular na Quinta Investigação, Husserl não tem nada de substantivo para dizer sobre os primeiros dois sentidos. Toda a sua teoria da consciência em 1901 é uma teoria da intencionalidade, ou seja, da referência a objetos através de um conteúdo significativo, nominal ou proposicional.

Basta, contudo, que Husserl, a partir de 1905, se abeire dos problemas da consciência interna do tempo para que comece a nascer uma teoria da autoconsciência. Essa teoria, ou melhor, essa descrição fenomenológica do modo como a vida psíquica aparece a si própria, não está já toda presente na parte do curso de 1905 que trata da consciência do tempo. Essa parte - a última de um curso intitulado Elementos Capitais da Fenomenologia e da Teoria do Conhecimento - tratava da consciência de um objeto temporal e discutia, nomeadamente, a tese de Meinong sobre a questão de saber se a consciência de um objeto temporalmente distribuído era, ela própria, um ato temporalmente distribuído. Meinong negara que o fosse e apostara na tese, contrária, da simultaneidade de um todo de consciência: um objeto temporalmente distribuído estaria consciente num ato temporalmente indistribuído, numa apre $\neg$ ensão final momentânea. Husserl, ao contrário, sustentará que a percepção de um objeto temporal é ela própria um processo temporal. Isso deixa-o com a questão de saber como a consciência representa a sua própria unidade ao longo do processo, ou seja, justamente a questão de saber como ela pode a si própria aparecer sob a forma de um fluxo temporal. É esta questão que abre as portas a uma nova teoria da autoconsciência.

O essencial dessa teoria foi obtido com a introdução dos conceitos de retenção e de protensão, a partir do ano de 1907. Até lá, Husserl trabalhara com os conceitos de memória fresca e de memória secundária, no quadro de um modelo sensualista em que se supunha que os "conteúdos primários" (os conteúdos de sensação) eram interpretados como "presente" ou como "mesmo agora passado" na apreensão de um objeto temporal. A crítica deste modelo, por volta de 1907-09, é contemporânea da introdução do conceito de "retenção". Na nova descrição, a percepção de um objeto temporal é um contínuo de fases em que o ponto-fonte é a consciência constitutiva do "agora" de cada vez atual do objeto. Husserl denomina-a "proto-impressão", à qual se conecta a retenção 
do "agora" anterior do objeto, ou, mais bem dito, à qual se conecta um outro "agora" dado com o sentido de "agora imediatamente anterior". Assim, em cada ponto de atualidade do objeto temporal aparece o momento presente da sua duração, digamos A, mas também, em simultâneo, aparece o momento B, como mesmo agora passado, e o momento $\mathrm{C}$, como mesmo agora passado de B. O objeto temporal deixa como que um rastro - ele tem um alongamento para lá do presente, e esse alongamento é a sua "cauda" de passado. É assim que ouvimos um som, uma frase ou uma melodia: cada ponto do objeto é acompanhado dos agora anteriores que aí estão presentes enquanto passados, pois se, à medida que chegamos aos novos momentos, os anteriores se apagassem, não teríamos consciência de objetos temporalmente estendidos como sons, frases ou melodias. Assim, a percepção de um objeto temporal pode ser descrita como um contínuo de fases que constrói a sua própria unidade, sem necessitar de uma ato final, momentâneo e sinóptico, como afirmara Meinong.

O ponto interessante é que, quando Husserl descreve a retenção, o seu brentanismo da percepção interna começa a inflectir-se. Desde sempre, Husserl é de opinião que a formulação brentaniana da autoconsciência conduz a uma regressão ao infinito. A dificuldade está ainda presente nos textos das Lições sobre a Consciência Interna do Tempo. Por exemplo:

Todo ato é consciência de qualquer coisa, mas todo ato está também consciente. Toda e qual $\neg$ quer vivên $\neg$ cia é "sentida", é imanentemente "percepcionada" (consciência interna), se bem que não seja, naturalmente, posta, visada (percepcionar não significa, aqui, estar-voltado-para-visando e captar) [...]. Certamente que isto parece reconduzir a uma regressão ao infinito. Porque não é agora, de novo, a consciência interna, o percepcionar do ato [...], um ato e, por isso, ele próprio outra vez percepcionado internamente e assim sucessivamente? ${ }^{7}$

A saída para esta dificuldade do modelo brentaniano da autoconsciência obteve-a Husserl, como disse, na sua teoria da retenção e, mais precisamente,

7 ,Jerder Akt ist Bewusstsein von etwas, aber jede Akt ist auch bewusst. Jedes Erlebnis ist „empfunden“, ist immanent „wahrgenommen“ (inneres Bewusstsein), wenn auch natürlich nicht gesetzt, gemeint (wahrnehmen heisst hier nicht meinend-zugewendet-sein und erfassen). [...] Freilich schient das auf einen unendlichen Regress zurückzuführen. Denn ist nun nicht wieder das innere Bewusstsein, das Wahrnehmen vom Akt [...] ein Akt und daher selbst wieder innerlich wahrgenommen usw.?" Husserl - Zur Phänomenologie des inneren Zeitbewusstesens (1893-1917). Band X. The Hague: Martinus Nijhoff, 1969, pp. 126-7. 
na sua descrição do que ele chamou de "dupla intencionalidade da retenção". De acordo com ela, a proto-impressão é a fase do ato dirigida sobre o momento "agora" do objeto temporal. Ela é consciência do ponto de atualidade do objeto. A retenção põe ao lado deste agora atual que aparece o agora acabado de passar, de tal modo que o objeto temporal aparece não como uma série de momentos sucessivos desligados, mas com uma profundidade temporal de momentos que se afundam mais e mais no passado. A este olhar para a declinação temporal do objeto chama Husserl a intencionalidade transversal da retenção: por ela aparece o objeto no seu presente e no seu passado. Mas a retenção tem também uma outra intencionalidade latente, e é esta a descoberta interessante de Husserl: o olhar pode voltar-se não para o objeto temporal que aparece, segundo a intencionalidade transversal da retenção, mas para a própria consciência que o visa na sua declinação temporal, e, então, o que aí aparece é a própria corrente de consciência, o fluxo de fases proto-impressionais retidas, na sua sucessão contínua, até a proto-impressão atual. Esta intencionalidade da retenção, pela qual aparece não o passado do objeto, mas o próprio fluxo de consciência, é precisamente o que Husserl designa como "intenciona-lidade longitudinal" da retenção.precisamente o que Husserl designa como "intencionalidade longitudinal" da retenção.

Pois bem, um aspecto importante desta doutrina de Husserl é, a meu ver, a revisão da terceira tese de Brentano que ela torna possível. A ideia central é que o fluxo de consciência só aparece quando um ato expressamente para ele se dirige pela intencionalidade longitudinal da retenção. Antes disso, não podemos dizer que o fluxo de consciência aparecesse já a si próprio numa autoconsciência de estilo brentaniano. Ele não é, portanto, um "fenômeno". Esta revisão faz-se a dois níveis. Primeiro, com a introdução do conceito de um "ser pré-fenomenal" das vivências ou dos atos de consciência, Husserl ultrapassa a ideia de que todo ato psíquico tem de aparecer a si próprio. De fato, para Husserl, antes do olhar que percorre a retenção segundo a sua intencionalidade longitudinal, $o$ ato não aparece nem é, por isso, um objeto secundário da consciência interna. Num texto das Lições, Husserl afirma-o:

Deve, por conseguinte, distinguir-se o ser pré-fenomenal das vivências, o seu ser antes do voltar-se reflexivo para elas, e o seu ser como fenômeno. ${ }^{8}$

8 „Es ist also zu scheiden: das präphänomenale Sein der Erlebnisse, ihr Sein vor der reflektiven Zuwen $\neg$ dung auf sie, und ihr Sein als phänomen."Idem, p. 129. 
O segundo elemento importante é que não poderemos mais dizer, em sentido próprio, que o ato esteja já consciente para uma forma de autoconsciência anterior à reflexão. Podemos quanto muito dizer que o ato se pré-constitui como algo que pode ser dado numa retenção, por via da intencionalidade longitudinal, e que pode tornar-se, desse modo, objeto temático de uma reflexão, ou seja, de um ato de segunda ordem que sobre ele incida. Antes, porém, o que está consciente é o objeto temporal, que é intencionalmente visado e que aparece segundo os seus horizontes temporais. $\mathrm{O}$ ato que o capta não é ainda fenômeno. Sê-lo-á apenas se a modalidade longitudinal da intencionalidade da retenção for atualizada e ele se tornar objeto de uma reflexão. E, aí sim, já não será o objeto temporal que aparece, mas o próprio fluxo em que há uma consciência desse objeto.

Assim, embora Husserl não o faça nunca de uma forma completamente explícita, uma revisão em profundidade da tese de Brentano torna-se possível a partir daqui. Não só não há fenômeno psíquico, ou seja, um aparecer do próprio ato antes de a intencionalidade longitudinal da retenção ter sido efetivada, como só há consciência de um fluxo de consciência e de um tecido de atos psíquicos para um segundo ato que os objetive na reflexão. Ou seja, antes da reflexão não há, propriamente, autoconsciência pré-reflexiva - há, sim, uma intencionalidade voltada para o objeto, na qual o fluxo de consciência se pré-constitui como objeto possível, mas sem que ele próprio apareça. Mesmo esta ideia de um fluxo de consciência con $\neg$ tínuo pode bem ser uma construção, com raízes na teoria da autoconsciência de Brentano, de que Husserl não chegou a liberar-se completamente. Ela é, no entanto, contra-intuitiva, pois realidades tão comuns como os intervalos de vigília e sono, que pontuam nossa vida de consciência, mostram com evidência que o chamado "fluxo de consciência" apresenta notáveis desconti-nuidades.

Eis então uma outra resposta para a possibilidade de reportar. Podemos reportar os nossos atos porque, ao recordar um objeto intencional, podemos fazer aparecer, ao lado do objeto visado, também o ato de o visar e o fluxo de consciência onde esse ato se insere. No entanto, esse ato não estava já consciente como um objeto secundário, mas apenas la $\neg$ tente na consciência dirigida para o objeto intencional. 


\section{O modelo projetivo da autoconsciência}

Farei, para terminar, uma apresentação positiva da minha tese. Ela não consiste numa negação de que haja qualquer coisa como uma autoconsciência anterior à captação reflexiva, mas antes numa reapreciação do seu modo de efetivação e do seu conteúdo concreto, tanto quanto uma descrição fenomenológica o pode fazer com sucesso. Em substância, direi que o sujeito da autoconsciência não está "atrás" dos objetos da consciência intencional, por assim dizer, acessível apenas numa consciência oblíqua ou pré-objectivante; o sujeito da autoconsciência está, antes, "em frente", nos próprios objetos da consciência intencional. Defendo, assim, que a consciência de objeto é "auto-posicional" e "auto-representativa", e que auto-posição e auto-representação se podem descrever como o ponto-de-vista a partir do qual a experiência de um mundo perceptivo circundante se organiza.

Para compreender isto, é necessário, contudo, desfazer algumas ideias que, em minha opinião, correspondem a outras tantas ilusões recalcitrantes. A primeira é que o mundo perceptivo é já o mundo objetivo que a ciência física descreve; a segunda, que os conceitos teóricos das diversas teorias explicativas são hauridos no mundo perceptivo e na sua organização intrínseca. Se puder remover essa dupla ilusão, ou seja, da objetividade do mundo perceptivo e da imediata acessibilidade, nele, dos objetos teóricos, poderei mostrar, de seguida, para esse mundo perceptivo, o modo como a auto-consciência está plasmada na consciência de objeto e como é um seu elemento essencial. Em suma, quero sugerir que a intencionalidade perceptiva não deve ser descrita como apresentação da realidade, mas antes como construção projetiva de um ambiente vital para o sujeito enquanto organismo psico-biológico.

Para o tornar mais visível, farei um curto périplo tendente a recuperar um conceito husserliano que é a todos os títulos central para os meus propósitos. Trata-se do conceito de "mundo da vida", que eu desenvolverei numa direção substancialmente diferente do tratamento que lhe foi dado por Husserl.

Deixem-me recordar, primeiro que tudo, que a Fenomenologia subscreve a ideia de que há uma experiência pré-teórica do mundo, não só anterior como independente de qualquer teoria explicativa. Esta ideia conheceu uma primeira expressão no positivismo de Ernst Mach, passou para o empiriocriticismo de Avenarius e deu origem ao programa de uma descrição do que este chamou o "conceito natural de mundo" (der natürliche Weltbegriff). Husserl retomou esse programa tipicamente positivista e desenvolveu-o em bases fenomenoló- 
gicas, desde 1911, com a descrição da organização perceptiva da expe-riência e com o conceito mais tardio de uma Lebenswelt, de um "mundo da vida", como forma primordial da doação do mundo enquanto correlato de uma experiência globalmente concordante. De acordo com ele, há uma experiência do mundo já semântica e categorialmente estruturada, mas independente de qualquer teoria. Ela permaneceria identicamente a mesma no seu teor de sentido e na sua estrutura típica ao longo da mu-dança das hipóteses explicativas. De fato, por exemplo, entre a Física de Aristóteles e a Física de Newton pouco há em comum no que diz respeito aos conceitos explicativos e aos próprios fatos objetivos, fixados a partir desses conceitos. No entanto, é argumen-tável que tanto Aristóteles como Newton tinham diante de si, na sua experiência pré-teó-rica, um mundo perceptivamente estruturado segundo padrões semelhantes, e que era finalmente aos objetos situados nesse mundo que as asserções das suas físicas se reportavam. Esta tese fenomenológica de raiz husserliana é plausível tanto quanto suprimamos a historicidade dos conceitos interpretativos usados na experiência pré-teórica e nos confinemos à estrutura perceptiva e à sua organização lógico-categorial. Faremos uso dela em seguida.

Relativamente a tal tese, faço as distinções seguintes.

Chamo "experiência-P” à captação perceptiva do mundo circundante, incluindo nessa captação o tipo de objetos que se constituem em percepções concordantes, mais as formas típicas de sequenciação de acontecimentos, mais as formações lógico-categoriais fundadas na doação dos objetos perceptivos. Grosso modo, os objetos dados no mundo circundante são objetos individuais, captados por conceitos pré-teóricos: "esta casa", "esta árvore”, "este azul”, etc.; os acontecimentos sequenciam-se segundo a forma-tipo do se, então: "se acontece que x, então y sucede", uma "indução" que não é ainda causalidade em sentido estrito; finalmente, as operações lógico-categoriais, baseadas na atividade judicativa, constituem objetos de segunda ordem: por exemplo, o substrato e a propriedade, o todo e a parte, a união conjuntiva, etc., objetos que, nos casos mencionados, são constituídos como correlatos de juízos predicativos, partitivos, conjuntivos. A experiência-P é, assim, experiência de um mundo confinado ao campo perceptivo ("circundante") e à sua dinâmica interna de progressão, composto de objetos individuais com consecução nos acontecimentos e objetos "lógico-categoriais", constituídos em operações judicativas.

Em contraposição, chamo "experiência-T" à reorganização da experiência-P a partir de uma teoria explicativa, a qual comporta uma ontologia específica (os objetos da teoria, por exemplo, ondas, partículas, centros de massa, etc., no 
caso da Física), mais uma estruturação da sequenciação dos acontecimentos (a pressuposição de leis causais ou simplesmente probabilísticas), mais uma linguagem para a expressão das regularidades notáveis (no caso da ciên $\neg$ cia moderna, a expressão matemática de relações entre grandezas mensuráveis).

Digo da relação entre elas o seguinte:

(i) A experiência-T é uma reinterpretação da experiência- $P$ : os objetos teóricos de T são supostos (literalmente: "sub-postos", "postos por baixo") nos objetos de P e "vistos" nestes.

(ii) A experiência-T não se substitui à experiência-P: os objetos de T são, as mais das vezes, objetos conceitualmente construídos por meio de idealizações e plenamente imperceptíveis, ou seja, insusceptíveis de serem dados em percepções.

(iii) A experiência-T tem de ter uma conexão, direta ou indireta, com a experiência- $P$ : um estado-de-coisas em $\mathrm{T}$ tem de poder ser perceptivamente apreendido por um estado-de-coisas em $\mathrm{P}$, que o evidencie direta ou indiretamente (dois exemplos: o núcleo das células é diretamente evidenciado num microscópio, enquanto uma linha de condensação na câmara de bolhas apenas torna indiretamente "visível" a trajetória de uma partícula subatómica).

(iv) A experiência-T tem uma gênese a partir da experiência- $P$ : os objetos de T são constituídos a partir de operações metódicas incidindo sobre os objetos de P.

Husserl, a propósito do mundo perceptivo, caracterizava-o como "subjectivo e relativo", em contraposição ao mundo que se constituía com o sentido de "objetivo e em-si", enquanto correlato das ciências matemáticas da natureza. "Subjetividade" não queria dizer que esse mundo fosse uma ilusão nas nossas mentes. Queria dizer, antes, que ele era uma função do ponto de vista do sujeito de experiência e que este ponto de vista desempenhava nele um papel essencial. Pretendo agora, para finalizar, caracterizar mais a fundo esta "subjetividade e relatividade" da experiência-P de um modo que permite perceber em que sentido uma representação pré-objectivante e pré-reflexiva de si está envolvida na representação perceptiva do mundo e joga nela um papel essencial.

Primeiro, começo com o mais óbvio: a estruturação espacial e temporal da experiência-P é relativa a um ponto-zero de orientação que marca a posição do sujeito. Esse ponto-zero de orientação é o sistema aqui-agora. O ponto-agora 
da experiência não pode ser confundido com os momentos fluentes do tempo. Enquanto estes vêm e passam, o ponto-agora é fixo e permanente: ele é a forma de atualidarde da vida de consciência, que é sempre uma vida no presente. Do mesmo modo para o "aqui" - ele não se confunde com um ponto do espaço, mas é o lugar de constituição corporal do sujeito da experiência como ponto permanente de orientação. Por esta via, dizer que toda a experiência-P se organiza a partir do sistema aqui-agora significa dizer que todos os objetos perceptivos são encontrados numa referência a esse ponto-zero subjetivo de orientação e que o exprimem justamente na medida em que são perceptivamente dados.

Segundo, a experiência-P contém, ainda, uma densa camada de estimações e valora-ções. De fato, mesmo que alguns objetos e estados-de-coisas sejam valorativamente neu-tros, uma porção significativa da experiência-P está organizada por predicados da esfera volitiva e valorativa: eles são belos ou feios, úteis, agradáveis, benfazejos ou perniciosos, etc. Esta coloração da experiência-P desenvolve uma auto-representação projetiva do sujeito sobre os objetos da sua experiência.

Terceiro, a experiência-P desenrola-se no quadro de uma projeção ativa em tarefas. Na verdade, o campo perceptivo, com a modulação em antecipações e memórias, não é simplesmente observado - ele é um campo de agência, ou seja, de intervenção e de consecução de acontecimentos a partir de intenções e de manipulações. Por exemplo, o corredor não é um simples espaço aberto, ele é algo que devo percorrer para chegar até a sala; o automóvel não está diante de mim como um objeto contemplado, mas como automóvel-em-que-devo-entrar para chegar a este ou aquele lugar, etc. A agência desempenha um papel essencial na experiência-P: ela faz das coisas utensílios ou obstáculos na projeção ativa do sujeito no mundo.

Por fim, quarto, a experiência-P está polarizada nas oposições eu-outro, nós-eles. A consciência de si não nasce na captação de um outro ego, mas conhece nela um momento de representação direta por contraposição. Do mesmo modo, o emparelhamento de sujeitos cria formas superiores de autoconsciência na representação de um "nós", a que se contrapõe um "eles". Tudo isso pertence à representação explícita, mas ainda pré-reflexiva, de um ego na experiência-P.

Organização espácio-temporal, rede de estimações e valorações, agência, projeção de si em tarefas, polarização eu-tu, meu-teu e constituição de sujeitos coletivos, para os quais de novo se constituem formas superiores de organização espácio-temporal, de estimações, tarefas, etc. - tudo isso faz com que a 
constituição perceptiva de um mundo circundante seja a constituição de um mundo "meu", e subsequentemente "nosso", de um mundo em que está presente uma "autoconsciência" ou, para o dizer de um modo mais terminante, de um mundo de tal modo estruturado que a experiência de objetos é, num sentido pertinente, o próprio lugar de desenvolvimento de uma consciência não-reflexiva de si. Ela assume a forma do ponto-de-vista: é esse o lugar primitivo do sujeito e a posse mais primordial de si. Em minha opinião, se procurarmos a forma nuclear da autoconsciência, será nesta dimensão projetiva e não nas teorias conjuntivas, provindas de Brentano, que a teremos de procurar. A experiência-P é impensável sem referência a um sujeito organizador, e esta organização não é apenas representativa; é ativa, valorativa, contém formas de sociabilidade e tudo isso é indissociável dela.

Para finalizar, voltando à pergunta desta minha comunicação - é a autoconsciência pré-reflexiva uma forma de intencionalidade? -, responderei: certamente, não porque o esquema intencional também se aplique à autoconsciência pré-reflexiva, mas sim porque é a própria intencionalidade que projeta sobre o mundo perceptivo uma auto-representação do sujeito: o mundo abre-se como "para mim", na "subjetividade e relatividade" do ponto-de-vista que, como que em sombra, se projeta no mundo. Tanto quanto, ingenuamente, pensemos que o mundo dado na consciência perceptiva é já o mundo objetivo que a ciência natural, e em particular a Física, conhece, esta tese parecerá estranha e difícil de aceitar. Mas se pensarmos que o mundo perceptivo é o resultado da nossa inserção ativa e categorizadora, enquanto seres biológicos e psíquicos, que ele é, em suma, um mundo vital, então duas coisas sucederão: começaremos a descrer progressivamente do valor da percepção para o conhecimento científico e a crer, inversamente, que o mundo perceptivo é forma como organizamos um ambiente vital a partir da nossa idiossincrasia biológica e psicológica, e que o modo como nos situamos a nós próprios nele está espelhado no modo como o organizamos, e que essa forma peculiar é a forma primitiva do "sentimento de si".

O fundo desta constituição de sentido mergulha na nossa história biológica e no nosso patrimônio genético enquanto espécie. Mas isso é, naturalmente, um fundo que está para lá do alcance do método fenomenológico de descrição. 
Brentano, Franz. Psychologie vom empirischen Standpunkt. Leipzig: Verlag von Duncker \& Humblot, 1874.

Gallaguer, Shaun ; Zahavi, Dan. The Phenomenological Mind. London: Routledge, 2008.

Husserl, Edmund. Logische Untersuchungen. Band XIX/1. The Hague: Mar-tinus Nijhoff Publishers, 1984. Zur Phänomenologie des inneren Zeitbewusstesens (1893-1917). Band X. The Hague: Martinus Nijhoff, 1969.

Sartre, Jean-Paul. La transcendence de l'ego. Esquisse d'une description phénoménologique. Paris : Vrin, 1966. 